\title{
Job Rents in a Stylized Labor Market
}

Ekkehart Schlicht

In: Beiträge zur Mikro- und Makroökonomik, edited by S. K. Berninghaus and M. Braulke, Berlin etc.: Springer-Verlag 2001, pp. 409-423

Electronic reprint 2006 December 2006

Department of Economics University of Munich

Volkswirtschaftliche Fakultät

Ludwig-Maximilians-Universität München

Online at http://epub.ub.uni-muenchen.de 


\title{
Job Rents in a Stylized Labor Market
}

\author{
EkKehart SCHLICHT*
}

Reprinted by permission. The original article appeared in Beiträge zur Mikro- und Makroökonomik, edited by S. K. Berninghaus and M. Braulke, Berlin etc., SpringerVerlag (C)2001, pages 409-423. All rights reserved.

\begin{abstract}
Wage formation is often analyzed by assuming that wage differentials reflect productivity differentials intrinsic to the workers, like differences in skill or qualification. Observed industry and firm effects on wages suggests, however, that wage differentials may result from causes rather unrelated to intrinsic productivity. This paper considers the polar case of homogeneous labor. The wage differentials emerging here are, thus, unrelated to individual differences. The model used is of an economy with a segmented labor market in which the primary sector industries are characterized by high turnover costs. This induces firms to pay efficiency wages reflecting turnover costs. The turnover case offers some rather surprising yet straightforward conclusions regarding efficiency, discrimination and taxation: Workers capture job rents; wage dispersion is too high; considerable wage differentials may arise from infinitesimally small differences in productivity; and a progressive wage tax will be welfare-enhancing.
\end{abstract}

JEL classification: $\mathrm{J} 31, \mathrm{~J} 41, \mathrm{~J} 63, \mathrm{~J} 71, \mathrm{H} 21, \mathrm{H} 24$

\footnotetext{
*Institutional Economics Group, Department of Economics, University of Munich, Schackstr. 4, 80539 Munich, Germany, email: schlicht@lmu.de. I thank Robert Frank, Marcus Mirbach, Peter Mücke, Ralph Wagner, Volker Woscidlo and Andreas Nicolin for helpful comment on earlier drafts.
} 
Introduction - i Overview - il The Model - il Optimum - iv Spurious
Correlation and Discrimination - v Heterogeneity and
Discrimination - vi A Wage Tax - vi Discussion - Concluding Remarks

\section{INTRODUCTION}

Many approaches to wage formation build on the assumption that wage differentials reflect productivity differentials intrinsic to the workers, like differences in skill or qualification. The discussion about industry effects and firm effects on wages suggest however that wage differentials may result from causes rather unrelated to intrinsic productivity. ${ }^{1}$ Thus, this paper considers the polar case of wage differentials arising in a framework of a segmented labor market and homogeneous labor, characterized by primary sector industries with high turnover costs. These turnover costs induce them to pay efficiency wages. ${ }^{2}$ The distinction of segmented labor markets along efficiency-wage lines is customary. ${ }^{3}$ I am going to stress, however, the turnover aspect rather than the discipline function of wages. This case offers some interesting conclusions regarding efficiency, discrimination and taxation and may be of some empirical relevance. ${ }^{4}$

It is argued, in particular

- that the existence of job rents induces distortions in prices and employment levels and associated inefficiencies;

- that discrimination can be triggered either by productivity related factors or by entirely arbitrary factors;

\footnotetext{
${ }^{1}$ See Bulow and Summers (1986), Dickens and Katz (1987), Murphy and Topel (1987), Lorenz and Wagner (1988), Katz and Summers (1989), Thaler (1989), OI (1990), Hübler and Gerlach (1990), Groshen (1991a,b), Krueger and Summers (1988), Blackburn and Neumark (1992), Schmidt (1992), Bellmann and Möller (1995), Moeller and Bellmann (1996), Abowd and Kramarz (2000). $\quad{ }^{2}$ For turnover efficiency wages, see Phelps (1968), Stiglitz (1974), Schlicht (1978), and Salop (1979); for discipline wages see Stoft (1982), Shapiro and Stiglitz (1984), and FeHr (1986). Surveys of efficiency wage theory are provided by Yelden (1984), and STiglitz (1987).

3 See Yellen (1984), Akerlof and Yellen (1986), Bulow and Summers (1986), Krueger and Summers (1988), and Albrecht and Vroman (1992) 4 See Campbell (1993).
} 
- that equilibrium data will exhibit a spurious correlation between arbitrary traits of the workers and productivity even if no real productivity differentials exist; and

- that a progressive wage tax will reduce job rents in equilibrium and will increase economic efficiency.

The results are obtained in a very stylized setting, where the allocative function of wages is restricted to their effect on product prices and consumer choice. In more realistic settings with heterogeneous labor, the wage structure may contribute to allocating labor concordant with comparative advantage. This aspect is faded out here in order to emphasize the rent aspect of wage formation. A more realistic treatment would require disentangling the favorable effects fostering comparative advantage and the adverse rent effects, but such an inquiry would outrange the compass of this paper.

\section{Overview}

The paper considers a set of segregated industries in the primary sector of an economy that differ only with respect to labor turnover costs. Labor is homogeneous. New entrants into the labor market enter one of the industries or the secondary competitive sector. If a new entrant does not succeed in obtaining a job in a high-paying primary industry, he settles for a lower-paying job in another primary industry or, at worst, for a job in the competitive sector which operates under standard competitive conditions. The firms in the primary sector industries pay different efficiency wages in order to optimally cope with differences in turnover costs. Although there is an excess supply of new applicants in those high-wage industries in equilibrium, the firms maintain their high wages in order to economize on turnover costs. This is modelled in section II.

Free entry to all industries causes prices to reflect wage differentials plus differentials in turnover costs. As a result, turnover costs enter total production costs twice, both indirectly as determinants of high wages, and directly as components of production costs. In section III it is argued that efficiency considerations would require labor inputs in all industries to be evaluated at the same shadow price, which is taken as the wage rate prevailing in the competitive sector. However, firms will use their actual wages, rather than the competitive wage rate, for evaluating labor inputs. This renders the products of high-wage industries too expensive. 
Free entry will, thus, bring about prices which reflect wage differentials. As the value-added per worker is evaluated at equilibrium prices, value-added per worker appears high in high-wage industries, and low in low-wage industries, in spite of the assumption of homogeneous labor. As the primary jobs are rationed in equilibrium, and labor is assumed to be homogeneous, applicants can be selected by using some arbitrary criterion. There is scope for costless discrimination. This is described in section IV. Further, if there is employment discrimination, in the sense that applicants for high-wage jobs are screened by an irrelevant feature, this feature will appear linked to the workers' productivity, in spite of its irrelevance.

In section $\mathrm{v}$ it is argued that small differences in productivity or turnover behavior between different groups of workers may induce quite inequitable treatment in equilibrium, with unpredictable efficiency implications.

In section vi it is argued that a progressive wage tax may help to alleviate the inefficiencies described in this paper because such a tax will render it more costly for the firms to control turnover by means of high wages, and this reduces the incentive to use high wages for these purposes. As a result, job rents will be abated and the wage structure will be flattened across industries. This attenuates inefficiencies.

The model presented in this paper has deliberately been devised such as to exhibit some mechanisms in a particularly simple and uncontaminated form. Section VII discusses issues that emerge if these stringent assumptions are relaxed. Some general problems relating more broadly to efficiency wage models are pertinent here. It is argued further that more realistic conditions will not eliminate the effects studied in this paper, but will lead to somewhat blurred and ambiguous conclusions. A brief summary follows.

\section{The Model}

Consider an economy with a set of industries, indexed by $i=1,2, \ldots, I$. Labor is homogenous. The number of firms in each industry is determined by a free entry/zero profit condition. The economy comprises, further, a competitive sector which offers the wage rate $w$ for labor. Thus, $w$ can be taken as an exogenous shadow price for labor in the subsequent argument. In order to rule out all effects stemming from different production technologies, all firms are assumed to produce according to the same continuous production function $f($ ), relating labor input $n$, to output $x$. Production exhibits decreasing marginal productivity and satisfies the 
Inada condition:

$$
\begin{array}{cll}
f>0, & f^{\prime}>0, & \text { and } \quad f^{\prime \prime}<0 \quad \text { for } n>0, \\
f(0)=0, & f^{\prime}(0)=\infty, \quad f^{\prime}(\infty)=0 .
\end{array}
$$

The typical firm in industry $i$ produces $x_{i}$ units of the industry output and employs $n_{i}$ units of labor:

$$
x_{i}=f\left(n_{i}\right) .
$$

All firms face labor turnover. Consider a typical firm in industry $i$. Its turnover rate is $\tau_{i}$. This will depend inversely on the wage rate $v_{i}$ offered by the firm in relation to the wage level $w_{i}$ prevailing in industry $i$

$$
\tau_{i}=\tau\left(v_{i} / w_{i}\right), \quad \tau^{\prime}<0
$$

The argument underlying this "black box" assumption is that there will be some "natural" turnover if all firms pay the same wage. If one single firm offers better terms, it can reduce turnover by delaying quits. ${ }^{1}$ Further, the workers in the different industries are assumed to form essentially non-competing groups. A particularly simple way to produce this feature is to assume that each firm prefers trained workers drawn from other firms from its own industry to untrained workers, and untrained workers to trained workers from other industries. As a result, each worker who has accepted a certain job when entering the labor force has the choice to remain in the chosen industry or join the lower-paying competitive sector, but is excluded from competing for other primary jobs. This-admittedly very restrictive-assumption renders the subsequent argument very transparent because it permits the supposition that turnover rates in any particular industry will depend only on the particular industry's wages and will be independent of the wages paid in other industries. (Section viI below will discusses a possible relaxation of this assumption.)

In order to concentrate on differences between industries, rather than on individual differences, it is assumed for the time being that the function $\tau(\cdot)$, describing turnover behavior, is identical across all industries. Industries differ only with respect to turnover costs. More specifically, turnover costs in industry $i$ are a multiple $c_{i}$ of the turnover rate. ${ }^{2}$ Total labor costs for a firm in industry $i$ employing $n_{i}$

\footnotetext{
${ }^{1}$ For more detailed argument, see Sснціснт (1978). ${ }^{2}$ The discussion in the preceding paragraph suggests that training costs for newcomers will be higher than those poached from other firms of the industry. Turnover costs $c_{i}$ should thus be interpreted as reflecting average turnover costs, given the usual mix of trained and untrained new hires. An explicit modelling would distract from the theme pursued here. See Schlicht (1981) for a treatment of this issue.
} 
workers are, thus, given by the sum of the wage bill $v_{i} n_{i}$ and turnover costs $\tau_{i} c_{i} n_{i}$ :

$$
\left(v_{i}+\tau\left(v_{i} / w_{i}\right) c_{i}\right) n_{i}
$$

In addition to labor costs, there are fixed costs of $q$ occurring in each firm. ${ }^{1}$ Total profits of a typical firm in industry $i$ are therefore

$$
p_{i} f\left(n_{i}\right)-\left(v_{i}+\tau\left(v_{i} / w_{i}\right) c_{i}\right) \cdot n_{i}-q \text {. }
$$

The typical firm maximizes this by choosing appropriate labor input $n_{i}$. Further, the firm maximizes profits by selecting an optimal firm-specific wage rate $v_{i}$, given the industry wage $w_{i}$, in order to control turnover. This leads to the necessary conditions for an inner maximum:

$$
\begin{gathered}
p_{i} f^{\prime}=v_{i}+\tau c_{i} \\
-\tau^{\prime}\left(v_{i} / w_{i}\right) c_{i}=w_{i}, \quad \tau^{\prime \prime}>0 .
\end{gathered}
$$

If the wage rate resulting from (6) and ( 7 ) is below the competitive wage, the firm is forced to pay the competitive wage rate $w$ in order to attract workers and a boundary solution obtains, with equation (7) replaced by the condition $w_{i}=w$.

The optimal wage rate $v_{i}$ is thus as a function of the industry wage $w_{i}$, turnover $\operatorname{costs} c_{i}$, and the competitive wage $w$ :

$$
v_{i}=\psi\left(w_{i}, c_{i}, w\right):=\max \left\{w, \phi\left(w_{i}, c_{i}\right)\right\}
$$

with

$$
\frac{\partial \phi}{\partial w_{i}}=\frac{v_{i}}{w_{i}}-\frac{w_{i}}{c_{i} v_{i} \tau^{\prime \prime}}
$$

where $\phi\left(w_{i}, c_{i}\right)$ refers to the interior solution of $(7)$. Starting with an industry wage rate $w_{i}$, each firm in the industry will select the optimal wage rate $v_{i}=\psi\left(w_{i}, c_{i}\right)$. For $v_{i}>w_{i}$, the industry wage level will increase; for $v_{i}<w_{i}$ it will decrease. $^{2}$ This is formalized in the following adjustment process with $\lambda>0$ as the speed of adjustment:

$$
\dot{w}_{i}=\lambda\left(\psi\left(w_{i}, c_{i}, w\right)-w_{i}\right) .
$$

\footnotetext{
1 This assumption seems appropriate because the firms can be supposed to incur other costs beyond wage costs. In a technical sense, the assumption is needed to generate a cost-minimizing employment level which is positive, although the analysis could be carried through in a formal sense without this assumption. $\quad 2$ Firms are thus assumed to have stationary expectations regarding the industry wage level. This prevents immediate adjustment. Staggered labor contracts may lead to a similar aggregate result.
} 
Equilibrium is given by:

$$
w_{i}=\max \left\{w,-\tau^{\prime}(1) c_{i}\right\}
$$

Those industries with rather low turnover costs will, thus, pay the competitive wage whereas firms with turnover costs exceeding a critical level will pay wages above the competitive wage. The set of industries may be classified accordingly. Renumber the industries such that the first $P$ industries have equilibrium wages above the competitive level, and the remaining $I-P$ industries have equilibrium wages that equal the competitive wage.

$$
\begin{array}{ll}
w_{i}=-\tau^{\prime}(1) c_{i}>w & \text { for } i=1,2, \ldots, P \\
w_{i}=w & \text { for } i=P+1, P+2, \ldots, I .
\end{array}
$$

The former set of industries forms the "primary" sector in the economy. All other firms may be lumped together with the competitive sector to form the "secondary" sector of the economy.

The wage changes in the primary sector around equilibrium are obtained from (7) and (8) as

$$
\frac{\partial \dot{w}_{i}}{\partial w_{i}}<0 \quad \text { at } w_{i}=\psi\left(w_{i}, c_{i}\right) \quad \text { for } i=1,2, \ldots, P
$$

Thus, $w_{i}$ increases if it is below equilibrium and decreases if above equilibrium, and the equilibrium industry wage (10) is stable for primary sector industries. It is also stable for the remaining industries because the competitive level sets the lower limit for wages, and (12) holds true above the competitive level.

The subsequent argument will concentrate on the primary sector industries $(i=1,2, \ldots, P)$ alone and take the competitive wage level as a given. Primary sector industries pay, thus, the equilibrium wage rate

$$
w_{i}=-\tau^{\prime}(1) c_{i}>w \quad \text { for all } i=1,2, \ldots, P .
$$

The difference between the industry wage $w_{i}$ and the competitive wage $w$ is the job rent $r_{i}$ :

$$
r_{i}:=w_{i}-w, \quad i=1,2, \ldots, P .
$$

Introduce the following notation for equilibrium turnover and equilibrium turnover sensitivity:

$$
\tau:=\tau(1), \quad \sigma:=-\tau^{\prime}(1)
$$


Assume free entry. This will drive prices to minimum unit costs:

$$
p_{i}^{*}=\min _{n_{i}}\left(\frac{\left(w_{i}+\tau c_{i}\right) n_{i}+q}{f\left(n_{i}\right)}\right)=\min _{n_{i}}\left(\frac{\left(w+r_{i}+\tau c_{i}\right) n_{i}+q}{f\left(n_{i}\right)}\right) .
$$

Since

$$
\frac{\partial^{2} p_{i}}{\partial n_{i}^{2}}=\frac{-p_{i} f^{\prime \prime}\left(n_{i}\right)}{f^{2}\left(n_{i}\right)}>0 \quad \text { at } \frac{\partial p_{i}}{\partial n_{i}}=0,
$$

the minimum is unique. Denote the corresponding labor input by

$$
n_{i}^{*}=\arg \min _{n_{i}}\left(\frac{\left(w_{i}+\tau c_{i}\right) n_{i}+q}{f\left(n_{i}\right)}\right)=\arg \min _{n_{i}}\left(\frac{\left(w+r_{i}+\tau c_{i}\right) n_{i}+q}{f\left(n_{i}\right)}\right) .
$$

The equilibrium price of industry $i$ can be written as

$$
p_{i}^{*}=\min _{n_{i}}\left(\frac{\left(\sigma c_{i} w_{i}+\tau c_{i}\right) n_{i}+q}{f\left(n_{i}\right)}\right), \quad i=1,2, \ldots, P .
$$

Thus, the minimum is increasing in the sensitivity to turnover $\sigma$, in turnover $\tau$, in fixed costs $q$, and in turnover costs, $c_{i}$ for all primary sector industries

$$
\frac{\partial p_{i}^{*}}{\partial \sigma}>0, \quad \frac{\partial p_{i}^{*}}{\partial \tau}>0, \quad \frac{\partial p_{i}^{*}}{\partial q}>0, \quad \frac{\partial p_{i}^{*}}{\partial c_{i}}>0
$$

\section{Optimum}

Consider now the social optimum. Take first employment per firm $n_{i}$ in all primary sector industries as given and fixed. It will be determined optimally, later.

If one additional firm is employed in industry $i$, this leads to additional output $f\left(n_{i}\right)$ and requires opportunity costs of labor $n_{i} w$, turnover costs $\tau c_{i} n_{i}$, and fixed costs $q$. Thus, one additional unit of output gives rise to additional social costs

$$
p_{i}=\frac{\left(w+\tau c_{i}\right) n_{i}+q}{f\left(n_{i}\right)} .
$$

A social planner will minimize these social costs by selecting the firm size in each industry optimally. Denote the corresponding optimal labor inputs by $\hat{n}_{i}$ and the corresponding socially optimal prices by $\hat{p}_{i}$.

$$
\begin{aligned}
& \hat{p}_{i}=\min _{n_{i}} \frac{\left(w+\tau c_{i}\right) n_{i}+q}{f\left(n_{i}\right)} \\
& \hat{n}_{i}=\arg \min _{n_{i}} \frac{\left(w+\tau c_{i}\right) n_{i}+q}{f\left(n_{i}\right)} .
\end{aligned}
$$


Compare these conditions with the equilibrium conditions for employment and prices, as given by (16) and (18). The formulae differ only in that optimality requires all wages to be equalized to the shadow price of labor, $w$, but equilibrium wages are higher. More specifically, from the definitions (22) of $\hat{p}_{i}$ and (19) of $p_{i}^{*}$ it follows that

$$
\hat{p}_{i}<\frac{\left(w+\tau c_{i}\right) n_{i}^{*}+q}{f\left(n_{i}^{*}\right)}<\frac{\left(w+r_{i}+\tau c_{i}\right) n_{i}^{*}+q}{f\left(n_{i}^{*}\right)}=p_{i}^{*}
$$

and hence

$$
p_{i}^{*}-\hat{p}_{i}>\frac{r_{i}}{f\left(n_{i}^{*}\right) / n_{i}^{*}}
$$

which implies that price distortion exceeds the job rent accruing per unit of output, evaluated at optimal labor input. The job rents $r_{i}$ induce, thus, two kinds of distortion: Higher wages are passed on to consumers in the form of higher prices. This distorts their choice of consumption. Further, high labor costs lead to suboptimal firm sizes in high-wage industries.

Popular notions of justice would, in this simple setting, suggest equal wages across industries, because labor is homogeneous. Competition induces, however, wage dispersion corresponding to the spread in turnover costs. There is a conflict between market outcomes and fairness notions. Such a conflict is quite common (KAHNEMAN et al., 1986). Usually we expect fairness notions to hamper efficient market outcomes. What is striking here is, however, that the market outcome is inefficient and an implementation of popular fairness notions such as 'comparable worth' legislation against the market would improve efficiency.

\section{iv Spurious Correlation and Discrimination}

Value-added per worker in industry $i$ is given by the difference between proceeds and non-labor costs per worker:

$$
\mu_{i}:=\frac{p_{i} f(n)-q}{n_{i}}-\tau c_{i} \quad i=1,2, \ldots, P .
$$

In equilibrium, equation (16) implies that wages correspond to value-added:

$$
w_{i}=\mu_{i}, \quad i=1,2, \ldots, P .
$$


While it appears as if value-added determines wages, causality actually runs in the other direction. Since labor is homogenous and the primary-sector jobs must be rationed, there is scope for costless discrimination. ${ }^{1}$

This case is of particular interest because conventional theories of discrimination imply efficiency, rather than inefficiency, of discrimination. ${ }^{2}$ Assume, for instance, that jobs are rationed according to "accent", where accent ranges continuously between $p$ and $q$ (for "pidgin" and "queen's", respectively). The result is a correlation between wage, value-added and accent, in which accent appears as having productive value. An arbitrary feature like accent may thus trigger significant discrimination, and empirical observations appear to reconfirm the (wrong) prejudice that the triggering feature is related to the worker's productive contribution.

\section{v Heterogeneity And Discrimination}

Discrimination theory has traditionally been concerned with studying differential treatment of economically identical individuals. It is, however, useful to conceive discrimination in a slightly broader way as comprising cases where slight individual productivity-related differences induce significant and systematic differential treatment. Discrimination which is triggered by some productivity-related trait may take a rather stubborn form. Consider first two groups of workers which differ solely with respect to their productivity. Index these groups by $m$ and $f$, respectively, where $m$ stands for "male" and $f$ stands for "female". Productivity of a female is $(1-\varepsilon)$ times the productivity of a male, with $\varepsilon>0$ arbitrarily close to zero. Denote the corresponding industry wages by $w_{i}^{m}$ and $w_{i}^{f}$, respectively, and denote the typical firm's wage offers by $v_{i}^{m}$ and $v_{i}^{f}$. Turnover of males and females is identical and is given by $\tau\left(v_{i}^{m} / w_{i}^{m}\right)$ and $\tau\left(v_{i}^{f} / w_{i}^{f}\right)$. Turnover costs are identical for males and females and are equal to $c_{i}$. The firm will be interested in minimizing unit costs of labor for males and females by selecting the gender-specific wage rates optimally:

$$
v_{i}^{f}+\tau\left(v_{i}^{f} / w_{i}^{f}\right) c_{i} \rightarrow \min _{v_{i}^{f}}
$$

\footnotetext{
${ }^{1}$ This is similar to Stiglitz's(1973) paper on efficiency wage discrimination. $\quad{ }^{2}$ E.g. taste discrimination (BeCKeR, 1971) or statistical discrimination (PhelPs, 1972).
} 
This leads to conditions analogous to $(7)$, and to an adjustment process analogous to (9). In equilibrium we must have $v_{i}^{m}=w_{i}^{m}$ and $v_{i}^{f}=w_{i}^{f}$; thus:

$$
w_{i}^{m}=w_{i}^{f}=\sigma \cdot c_{i} \text {. }
$$

Consequently, efficiency wage reasons would lead to the identical equilibrium wages for men and women in equilibrium, in spite of women being infinitesimally less productive than men. The reason is that firms optimize with respect to turnover costs, and these are identical for males and females, leading to identical wage policies for males and females.

Women are, however, assumed to be slightly less productive than men. As firms have a choice to hire either men or women, they will prefer men, and job discrimination results. Women will not be hired and are forced to accept other jobs which less compensation. In this way, very small productivity differentials can trigger significant differential treatment.

Consider now the case that the groups differ not with respect to intrinsic productivity, but with regard to turnover behavior. Slight differences in this respect may again trigger job discrimination. This would again induce job discrimination, in spite of equal productivity.

Denote the relevant gender-specific sensitivities of turnover to wage changes by $\sigma^{m}$ and $\sigma^{f}$, and the corresponding turnover rates by $\tau^{f}$ and $\tau^{f}$ (see (15)). Equilibrium wages for men and women are now $w_{i}^{m}=\sigma^{m} \cdot c_{i}$ and $w_{i}^{f}=\sigma^{f} \cdot c_{i}$, respectively. Costs entailed by employing one male worker amount to $\left(\tau^{m}+\sigma^{m}\right) c_{i}$. Analogously, a female worker costs $\left(\tau^{f}+\sigma^{f}\right) c_{i}$. The associated turnover costs are $\sigma^{m} c_{i}$ and $\sigma^{f} c_{i}$

Males are preferred over females whenever total labor costs are lower for males. Total labor costs are the sum of wages and turnover costs. Consider two cases where this occurs and males are preferred over females.

The first case is characterized by comparatively low turnover costs for males:

$$
\tau^{m}<\tau^{f} \quad \text { and } \quad \sigma^{m}>\sigma^{f} \quad \text { with } \quad\left(\tau^{m}+\sigma^{m}\right)<\left(\tau^{f}+\sigma^{f}\right)
$$

In this case, men are cheaper to employ than women and thus preferred over women, although their equilibrium wage is higher. Women will have higher turnover. The associated higher costs outweigh their lower wages, and males are preferred. It is socially optimal to discriminate against women because this saves turnover costs for society. 
Another case would be that turnover costs of males exceed those of females, but their sensitivity to wage changes is less:

$$
\tau^{m}>\tau^{f} \quad \text { and } \quad \sigma^{m}<\sigma^{f} \quad \text { with } \quad\left(\tau^{m}+\sigma^{m}\right)<\left(\tau^{f}+\sigma^{f}\right) .
$$

Here, men are again cheaper and will be preferred, although their employment entails higher turnover costs. The resulting employment discrimination of women is socially inefficient. The turnover perspective thus leads to insights regarding discrimination that complement related arguments developed from a shirking perspective. $^{1}$

\section{A Wage Tax}

Consider the welfare effects of a wage tax. There is a tax function $z()$ which gives, for any wage level, the corresponding wage tax. Assuming that after-tax wages determine turnover behavior. With the previous notation, we may re-write (3) as:

$$
\tau_{i}=\tau \frac{v_{i}-z\left(v_{i}\right)}{w_{i}-z\left(w_{i}\right)}, \quad i=1,2, \ldots, P .
$$

If we calculate the equilibrium wage rate similarly to (5)-(10), we obtain instead of (10) the equilibrium condition

$$
w_{i}=\frac{1-z^{\prime}(w)}{1-z\left(w_{i}\right) / w_{i}} \cdot \sigma c_{i}, \quad i=1,2, \ldots, P .
$$

Without a tax, the equilibrium wage in industry $\mathrm{i}$ has been determined as $w_{i}=$ $\sigma c_{i}$. A progressive wage tax, i.e. a tax with $z^{\prime}\left(w_{i}\right)>z\left(w_{i}\right) / w_{i}$, will reduce wage differentials. However, this has no impact on turnover costs, since it is only relative wages within each industry that matter, and these remain unaffected. ${ }^{2}$ Wages are, however, brought closer to their competitive level. This removes associated price and employment distortions and results in efficiency gains from taxation. ${ }^{3}$

\section{Discussion}

Bonding. The model is driven by the assumption that wage differentials across industries persist because firms use wages to control turnover. However, there

\footnotetext{
${ }^{1}$ Bulow and Summers $(1986,99-401) . \quad{ }^{2}$ This is similar to the neutral allocation effect of self-selection discussed in (SALOP and SALOP, 1976). ${ }^{3}$ With regard to unemployment and taxation in an efficiency-wage setting, see (Hoel, 1990).
} 
may be other means to render all jobs equally attractive, and private incentives to introduce such measures. Firms may ask for entrance fees to capture the job rents accruing to the workers, or they may ask for bonding. This problem has been discussed extensively in the context of efficiency wage theory. ${ }^{1}$

If these mechanisms lead to an equalization of utility across careers, the present argument would break down. Casual empiricism suggests that bonding, seniority pay and similar measures are actually used, but not to the point of entirely eliminating utility differentials across careers. As long as such utility differentials (i.e., those not due to "intrinsic" differences in productivity), persist, arguments of the type developed in this paper are relevant. In contrast to the present paper, reality presents a set of complex, rather than stylized, cases.

The main theoretical argument supporting the present view relates to what Stiglitz $(1987,30)$ has termed the "double moral hazard problem". For example, if the firm uses seniority pay as a bonding instrument, this may help to reduce turnover costs. It may, however, also make firms interested in getting rid of the overpaid senior workers. ${ }^{2}$ A prohibition on firing senior workers is, however, harmful for work incentives. Job purchases must also be combined with a safeguard against firing. This is again detrimental for performance incentives. ${ }^{3}$ Fairness considerations may further restrict contracting. ${ }^{4}$ All this limits the scope for seniority pay as a bonding mechanism and lends plausibility to the assumption that utility differentials across careers may persist.

Heterogeneity. The presented argument does not depend too strongly on homogeneity. The corresponding assumptions have been made primarily to eliminate all "standard" explanations for wage differentials and render the argument in this way more transparent.

If each industry has a specific production function $f_{i}\left(n_{i}\right)$, different from that of other industries, and specific fixed costs $q_{i}$, all equations remain valid in the sense that production functions and fixed costs are to be indexed appropriately. The results on wage determination (10), price distortion (16), (22), and the equivalence between value-added and the wage rate (18), (23) remain unaffected. Thus, the general conclusions remain the same.

Differences in turnover propensities between industries can be handled similar to differences in turnover propensities between men and women in the discussion

\footnotetext{
${ }^{1}$ Stiglitz $\left(1987,29\right.$ f.) for a review. ${ }^{2}$ Lazear (1979) has analyzed mandatory retirement. The practice points in this direction. In Germany, a court has declared the usual mandatory retirement provisions in labor contracts illegal. This has enabled workers to obtain considerable amounts of money as compensation for their consent to early retirement (Süddeutsche Zeitung, 1994, 1).

3 SChlicht and von Weizsäcker (1977, 60-1). ${ }^{4}$ Gächter and Kirchsteiger (1996).
} 
of discrimination (Section Iv). Differences in "intrinsic" productivity between workers can also be introduced. This would, however, undermine the welfare implications which depend crucially on the assumption that wage differentials have no positive allocative role to play. Once a positive allocative function of wages is taken into account, results will be mixed. It seems to be clear, however, that wages reflecting other things than scarcities will induce firms to misallocate labor because they take the wages as scarcity indicators in their own calculations. In this sense, the existence of job rents indicates efficiency losses. More generally, we may allow for productivity differentials across workers, turnover cost differentials across firms, and the possibility of workers to move between industries which would render turnover in each industry dependent upon all other wage rates. ${ }^{1}$ However, the case of turnover cost differentials between men and women (Section IV) carries ambiguous efficiency consequences already, and we should, thus, not expect any clear-cut efficiency result under even more general circumstances.

Taxation. The result that a more progressive wage tax will flatten the wage profile before taxes is in striking contrast to presumptions informed by human capital theory. Yet it is fairly general in the sense that it should carry over to many types of efficiency wage models. ${ }^{2}$ The argument is that once wages are used as instruments, and the efficacy of these instruments is reduced by raising progressivity, the instruments will be used less intensely.

\section{Concluding Remarks}

Turnover costs may lead to wage formation in such a way that wages are determined by turnover propensities. This permits workers to capture inefficient job rents. Price distortions and discrimination (both efficient and inefficient) may result. A progressive wage tax may be welfare enhancing. All this challenges the conventional view of wage formation, but the model is admittedly stylised. Its purpose has been simply to highlight the orthogonal case.

\footnotetext{
${ }^{1}$ In other words equation (3) describing turnover in each industry as solely dependent on the typical firms wage $v_{i}$ and the industry wage $w_{i}$ can be replaced by the more general assumption $\tau_{i}=\tau\left(v_{i} / w_{i} ; w_{1}, w_{2}, \ldots, w_{i-1}, w_{i+1}, \ldots, w_{I}\right)$ which permits workers flow across industries. Such a formulation would not alter formal analysis with regard to the equilibria, but the corresponding dynamic adjustment (the analogue to equations (8)-(12)) is complex. ${ }^{2}$ This would hold true in the model by ScHLicht (1981), for example.
} 


\section{REFERENCES}

Aвowd, J. C. and F. Kramarz 2000, "Inter-industry and Firm-size Wage Differentials in France and the United States," Paper presented at the EALE-SOLE World Conference Milan (Italy), June 2000, 22-25.

Akerlof, G. A. and J. Yellen (eds.) 1986, Efficiency Wage Models of the Labor Market, Macmillan, New York etc.

Albrecht, J. W. and S. B. Vroman 1992, "Dual Labor Markets, Efficiency Wages, and Search," Journal of Labor Economics, 10, 438-61.

Becker, G. S. 1971, The Economics of Discrimination, Chicago University Press, Chicago.

Bellmann, L. and J. Möller 1995, "Institutional Influences on Interindustry Wage Differentials," in: F. Buttler, W. Franz, R. Schettkat, and D. Soskice (eds.), Institutional Frameworks and Labour Market Performance, pp. 132-67, Routledge, London.

Blackburn, M. and D. Neumark 1992, "Unobserved Ability, Efficiency Wages, and Interindustry Wage Differentials," Journal of Economics, 107, 1421-36.

Bulow, J. I. and L. H. Summers 1986, "A Theory of Dual Labor Markets with Application to Industrial Policy, Discrimination, and Keynesian Unemployment," Journal of Labor Economics, 4, 376-414.

Campbell, C. M. 1993, "Do Firms Pay Efficiency Wages? Evidence with Data at the Firm Level," Journal of Labor Economics, 11, 442-70.

Dickens, W. T. and L. F. Katz 1987, "Inter-Industry Wage Differences and Industry Characteristics," in: J. S. LEONARD and K. LANG (eds.), Unemployment and the Structure of Labour Markets, pp. 48-89, Blackwell, Oxford.

FeHr, E. 1986, “A Theory of Involuntary Equilibrium Unemployment,” Journal of Institutional and Theoretical Economics, 142, 405-30.

Gächter, E. F. S. and G. Kirchsteiger 1996, "Reciprocal Fairness and Noncompensating Wage Differentials," Journal of Institutional and Theoretical Economics, $152,608-40$. 
Groshen, E. L. 1991a, “Five Reasons Why Wages Vary Among Employers,” Industrial Relations, 30, 350-81.

— 1991b, "Sources if Intra-Industry Wage Dispersion: How Much Do Employers Matter?" Quarterly Journal of Economics, 106, 869-84.

Hoes, M. 1990, "Efficiency Wages and Income Taxes," Journal of Economics, 51, 89-99.

Hübler, O. and K. Gerlach 1990, "Sectoral Wage Patterns, Individual Earnings and the Efficiency Wage Hypothesis," in: H. KöNIG (ed.), The Economics of Wage Determination, pp. 105-27, Springer, Berlin.

Kahneman, D., J. L. Knetsch, and R. Thaler 1986, "Fairness as a Constraint on Profit Seeking: Entitlements in the Market," American Economic Review, 76, $728-41$.

Katz, L. F. and L. H. Summers 1989, "Industry Rents: Evidence and Implications," Brookings Papers on Economic Activity, Special Issue, 205-75.

Krueger, A. B. and L. Summers 1988, "Efficiency Wages and the Inter-Industry Wage Structure," Econometrica, 56, 259-93.

Lazear, E. P. 1979, "Why Is There Mandatory Retirement?" Journal of Political Economy, 87, 1261-84.

Lorenz, W. and J. WAGNer 1988, "Gibt es kompensierende Lohndifferentiale in der Bundesrepublik Deutschland?” Zeitschrift für Wirtschafts- und Sozialwissenschaften, 108, 371-81.

Moeller, J. and L. Bellmann 1996, "Qualifikations- und industriespezifische Lohnunterschiede in der Bundesrepublik Deutschland," Ifo-Studien, 42, 235-72.

Murphy, K. M. and R. H. Topel 1987, "Unemployment, Risk, and Earnings: Testing for Equalizing Wage Differences in the Labor Market," in: J. S. Leonard and K. LANG (eds.), Unemployment and the Structure of Labour Markets, pp. 103-40, Blackwell, Blackwell.

Oı, W. Y. 1990, “Employment Relations in Dual Labor Markets ('It's Nice Work If You Can Get It')," Journal of Labor Economics, 8, 124-49. 
Phelps, E. S. 1968, "Money-Wage Dynamics and Labor-Market Equilibrium,” Journal of Political Economy, 76, 678-711.

— 1972, "The Statistical Theory of Racism and Sexism," American Economic Review, 62, 659-61.

Salop, J. and S. SAlop 1976, "Self-Selection and Turnover in the Labor Market," Quarterly Journal of Economics, 90, 619-27.

Salop, S. 1979, "A Model of the Natural Rate of Unemployment," American Economic Review, 69, 117-25.

Schlicht, E. 1978, "Labour Turnover, Wage Structure, and Natural Unemployment," Journal of Institutional and Theoretical Economics, 134, 337-46, online at http: //econpapers.repec.org/paper/lmumuenec/1255.htm.

— 1981, "Training Costs and Wage Differentials in the Theory of Job Competition," Zeitschrift für die gesamte Staatswissenschaft (Journal of Institutional and Theoretical Economics), 137, 212-21, online at http://epub.ub.uni-muenchen.de/oooo1347/.

Schlicht, E. and C.-C. von Weizsäcker 1977, "Risk Financing in Labour Managed Economies: The Commitment Problem," Journal of Institutional and Theoretical Economics, pp. 55-66.

Schmidt, E. M. 1992, “Intersektorale Lohndifferentiale," Zeitschrift für Wirtschaftsund Sozialwissenschaften, 112, 201-18.

Shapiro, C. and J. E. Stiglitz 1984, "Equilibrium Unemployment as a Worker Discipline Device," American Economic Review, 74, 433-44.

Stiglitz, J. E. 1973, "Approaches to the Theory of Discrimination," American Economic Review, 63, 287-95.

- 1974, "Alternative Theories of Wage Determination and Unemployment in LDC'S: The Labor Turnover Model," The Quarterly Journal of Economics, 88, 194-227.

- 1987, "The Causes and Consequences of the Dependence of Quality on Price," Journal of Economic Literature, 25, 1-48.

Stoft, S. 1982, "Cheat-Threat Theory: Techniques for Modeling Involuntary Unemployment," Discussion paper 82, Boston University, Department of Economics. 
Süddeutsche Zeitung 1994, “Zwangsruhestand mit 65," 50, 1.

Thaler, R. H. 1989, "Interindustry Wage Differentials," Journal of Economic Perspectives, 3, 181-93.

Yellen, J. L. 1984, “Efficiency Wage Models of Unemployment," American Economic Review, 74, 200-05. 